\title{
Respiratory symptoms and pulmonary function of welders in the engineering industry
}

\author{
SP HAYDEN, AC PINCOCK, J HAYDEN, LE TYLER, KW CROSS, JM BISHOP \\ From the Departments of Medicine and Social Medicine, University of Birmingham, and Medical \\ Headquarters, Guest Keen and Nettlefolds Ltd, Warley, West Midlands
}

ABSTRACT We have studied respiratory symptoms, smoking habits, chest radiographs, sickness absence, and pulmonary function among 258 welders and an equal number of matched control subjects in three engineering factories. Welders who smoked had a higher frequency of chronic phlegm production than control subjects but there was no difference in cough or dyspnoea. The frequency of abnormality on chest radiographs was low and similar in welders and controls. Upper respiratory infections were a more frequent cause of sickness absence in welders than in controls but no difference was found in other respiratory diseases. $\mathrm{FEV}_{1}$ and peak expiratory flow rate were similar in welders and controls. In a subset of 186 subjects the maximum expiratory flow rate at low lung volumes was significantly less in welders who smoked than in control subjects who smoked, but there was no difference in non-smokers. Welders working under these conditions in the engineering industry appear to have no increased risk of chronic obstructive lung disease.

Some constituents of welding fume are potentially harmful ${ }^{1-5}$ and there has been increasing concern that even low concentrations could result in an increased frequency of chronic bronchitis and emphysema. Evidence in favour of a harmful effect of welding is contained in the reports on occupational mortality of the Registrar General for England and Wales, several of which have shown an increased frequency of death from pneumonia. The most recent report shows, in addition, an increased frequency of death from cancer of the respiratory tract. ${ }^{\circ}$

There have been several surveys of the health of welders over the last 40 years. $^{7-11}$ Most have concentrated on welders who work in shipyards, where conditions differ from those found in factories making light or medium engineering products. The most notable difference is that shipyard welders generally work in enclosed spaces. There has been no previous large scale survey of respiratory disease in welders in the engineering industry.

The present study compares welders and nonwelders in the same factories working under condi-

Address for reprint requests: Professor JM Bishop, Department of Medicine, Queen Elizabeth Hospital, Birmingham B15 2TH.

Accepted 24 January 1984 tions which were generally similar. Respiratory symptoms, sickness absence, chest radiographs, and pulmonary function were studied and related to particular circumstances of welding exposure.

\section{Methods}

POPULATION AND SUBJECTS STUDIED

The subjects worked at three factories making products for the automotive and related industries. The largest factory, which provided about half of the subjects, was in Telford in Shropshire, while the two $\frac{7}{0}$ others were about 40 miles away at Wolverhampton in the West Midlands, which is an area of longstand- o ing medium and heavy industry. Although some $N$ workers at Telford had spent much of their life in $N$ the industrial area of the West Midlands before $\omega$ moving to Telford most had always lived in the semi-rural surrounding area.

The welders mostly used one or other form of arc $\stackrel{D}{\Phi}$ welding process and worked in open booths or on jigs in large buildings with a high roof and good $\frac{0}{\circ}$ general ventilation. A few were spot welders on a $\vec{D}$ production line and others worked on large projects $\frac{\rho}{\mathbb{Q}}$ which could not be moved easily. The control sub- $\varrho$ jects were all from the same factories and each was selected to match a welder on the basis of age and 8 
Table 1 The survey population

\begin{tabular}{lllr}
\hline & Welders & Controls & Total \\
\hline Total invited & 361 & 685 & 1046 \\
Declined invitation & 103 & 427 & 530 \\
Study population & 258 & 258 & 516 \\
Wolverhampton & 130 & 130 & 260 \\
Telford & 128 & 128 & 256 \\
\hline
\end{tabular}

proximity of work. Most controls were working in the same sections as the welders for at least part of the time. The occupations of control subjects were varied but all were directly concerned with manufacturing processes, maintenance, or toolroom work. Those engaged in occupations allied to welding or who had previously been welders were excluded.

\section{SELECTION OF SUBJECTS}

After detailed agreement on the form of the investigation with representatives of trades unions and management the investigators were supplied with complete lists of all welders and non-welders by the personnel department. In the Wolverhampton factories all the welders were personally invited to take part in the study; at Telford a letter was sent to all welders explaining the project and inviting participation. Control subjects were then approached in the same way so that both groups were studied concurrently. Each welder who agreed to take part was matched with a non-welder of the same sex, racial origin, and age (to within 10 years). So far as possible the non-welders also worked in the same workshop. The few women, and men of non-European origin, were excluded to maintain a homogeneous study population. Of the total of 361 welders employed, 258 agreed to take part (table 1).

\section{PROCEDURE}

A questionnaire was administered to each subject. For 227 of the 258 subjects this was done by one investigator, SPH. Pulmonary function tests were then performed. A standard posteroanterior chest radiograph was obtained for all subjects and read independently by two observers according to the ILO/UC classification of 1971 , with reference to a standard set of films. Sickness absence records were obtained for all welders and control subjects and for those who had declined to take part in the study. A letter and short questionnaire were forwarded by the Department of Health and Social Security to each welder who had left employment with the company during the past five years. Too small a number replied to provide useful data and for reasons of confidentiality we were not provided with addresses and so were unable to take further action.

\section{QUESTIONNAIRE}

The questionnaire was the 1966 Medical Research Council questionnaire on respiratory symptoms with additional questions about the type and extent of welding training and precautions adopted by the welder to reduce fume inhalation, and about his knowledge of and attitude to welding.

\section{CERTIFIED SICKNESS ABSENCE}

The number of days lost from work as a result of sickness absence in the preceding two years was obtained from the factory medical records of all welders and controls, whether they took part in the study or not. The diagnosis was taken as that of the certifying doctor and the absence was classified as having a non-respiratory or a respiratory cause. Non-respiratory causes were subdivided into injuries, rheumatic disorders, and others. Respiratory causes were subdivided into upper respiratory infections (coryza, pharyngitis, tonsillitis), influenza, chest illness (bronchitis, asthma, pneumonia, emphysema) and other respiratory illness (for example, pneumothorax, pulmonary embolism).

\section{PULMONARY FUNCTION TESTS}

The vitalograph dry wedge spirometer was used to measure forced expiratory volume in one second $\left(F_{1} V_{1}\right)$, and this was corrected to BTPS. Three spirograms were obtained after two practice attempts, and the mean of the three measurements was used to express the result. Peak expiratory flow (PEF) was measured with a Wright peak flow meter and the mean of three measurements was taken after two practice attempts.

In 186 of the subjects (105 welders and 81 controls) at the Telford factory flow-volume curves were also obtained. The output of an 840 Ohio waterless spirometer (Airco, Montvale, New Jersey) was digitised and recorded on magnetic tape for subsequent analysis by computer. The measurements produced in this manner were maximum expiratory flow when $50 \%$ and $25 \%$ of the vital capacity remained to be expired $\left(\mathrm{MEF}_{50}\right.$ and $\left.\mathrm{MEF}_{25}\right)$. The final result for each subject was the mean of the flows taken from the two attempts with the highest $\mathrm{FEV}_{1}$, provided that the FVC in the two attempts agreed to within $10 \%$.

Measured values for $F E V_{1}$ were adjusted by dividing them by height squared $\left(\mathrm{FEV}, / \mathrm{H}^{2}\right) .^{12}$ For other comparisons $\mathrm{FEV}_{1}$ was standardised for height and age to give the standardised FEV (SFEV). The regression equation used ${ }^{13}$ was

$\mathrm{FEV}_{1}=3.26 \times$ height $_{(\mathrm{m})}-0.031 \times \operatorname{age}_{(\mathrm{y})}-1.41$.

All the measured values for $\mathrm{FEV}_{1}$ were adjusted on 
the basis of the individual values of height and age to the mean height and mean age of the combined population of welders and controls. Values of PEF were treated in a similar way, a regression equation having been derived from the measured values in the welders and control subjects in the form

PEF $=6.499 \times$ height $_{(m)}-0.049 \times \operatorname{age}_{(y)}-0.730$.

All statistical procedures (including the Student's $t$ test, $\chi^{2}$ test, and linear and multiple regression analysis) were carried out with the Statistical Package for the Social Sciences (SPSS). Validation procedures were first performed and errors corrected. ${ }^{14}$

\section{Results}

The subjects in the study population were compared for age and rates of sickness absence with those who did not take part. There was no difference between the means and distributions of ages of the study group and of those who did not take part. The study population lost slightly fewer days from all kinds of sickness absence but this was not a significant difference.

Height was normally distributed in welders and controls and the mean height was identical in the two groups (1.722 (SD 0.068)). No difference was found between the number of welders and the number of controls in. each smoking category (cigarette, pipe, or cigar). The numbers of smokers, ex-smokers, and lifelong non-smokers were almost identical in the study and control groups and daily and lifetime tobacco consumption among smokers was very similar (table 2 ). The number of men who had worked in dusty occupations with known respiratory hazards was similar in the welders and controls.

\section{RESPIRATORY SYMPTOMS}

The frequency of cough as a symptom was similar in welders and control subjects but welders who

Table 2 Smoking history of study population

\begin{tabular}{lcc}
\hline & Welders & Controls \\
\hline Never smoked & 45 & 45 \\
Ex-smokers & 76 & 73 \\
Current smokers & 137 & 140 \\
Do not inhale & 21 & 32 \\
Inhale slightly & 19 & 14 \\
Inhale moderately & 70 & 62 \\
Inhale deeply & 27 & 32 \\
Mean (SD) daily tobacco & $17.3(8 \cdot 8)$ & $18.5(10 \cdot 3)$ \\
$\quad$ consumption (g) & $20.8(14 \cdot 6)$ & $21.4(17.0)$ \\
Mean (SD) lifetime tobacco & & \\
consumption (pack years) & &
\end{tabular}

Table 3 Frequency of small round and regular small opacities in chest radiograph

\begin{tabular}{|c|c|c|c|}
\hline & Welders & Controls & Total \\
\hline $\begin{array}{l}\text { Reader } 1 \\
\text { Probably abnormal } \\
\quad \text { (profusion } 1 / 0 \text { or more) }\end{array}$ & 4 & 1 & 5 \\
\hline $\begin{array}{l}\text { Probably normal } \\
\quad \text { (profusion } 0 / 0 \text { or } 0 / 1 \text { ) }\end{array}$ & 220 & 235 & 455 \\
\hline Total $^{*}$ & 224 & 236 & 460 \\
\hline $\begin{array}{l}\text { Reader } 2 \\
\text { Probably abnormal } \\
\quad \text { (profusion } 1 / 0 \text { or more) }\end{array}$ & 27 & 23 & 50 \\
\hline $\begin{array}{l}\text { Probably normal } \\
\text { (profusion } 0 / 0 \text { or } 0 / 1 \text { ) }\end{array}$ & 188 & 196 & 384 \\
\hline Total $^{*}$ & 215 & 219 & 434 \\
\hline
\end{tabular}

smoked had a higher frequency of chronic phlegm production than controls who smoked ( $p<0.05)$. No difference in phlegm production was found when non-smokers in the two groups were compared. The prevalence of dyspnoea, chest illness, chest episodes, and wheezing was similar in welders and controls, as was a previous history of bronchitis, pneumonia, asthma, emphysema, and pleurisy.

\section{CHEST RADIOGRAPHY}

The results obtained by each of the two readers are summarised in table 3 . The number with small round opacities at a profusion of $1 / 0$ or more was not significantly different between welders and controls $(p>0.05)$. There was a significant difference between the two readers in the numbers of radiographs reported as abnormal. The reader who found a higher frequency of abnormality checked his results by reading again 25 of the abnormal films together with 48 films previously recorded as normal. All the films reported as $0 / 0$ on the first occasion were again read as $0 / 0$. Ten of the 25 films previously reported as slightly abnormal were then read as probably normal $(0 / 1)$.

\section{SICKNESS ABSENCE}

The only significant difference in sickness absence between welders and controls was that welders lost more days due to upper respiratory infection. The total absence due to all respiratory illness was the same in the two groups. When the welders and controls together were subdivided by smoking habit, smokers had almost double the sickness absence of non-smokers (28.5 and 15.0 days respectively). Welders who smoked had more frequent sickness from rheumatic disease $(10.33$ days) than the corresponding controls $(2.39$ days, $\mathrm{p}<0.05)$, but the rates for respiratory illness were similar. 
Table 4 Values for selected tests of pulmonary function amongst welders and control subjects by smoking habits

\begin{tabular}{|c|c|c|c|c|c|c|c|c|c|}
\hline & & \multicolumn{4}{|l|}{ Welders } & \multicolumn{4}{|l|}{ Controls } \\
\hline & & Smokers & Non-smokers & Ex-smokers & All & Smokers & Non-smokers & Ex-smokers & All \\
\hline $\begin{array}{l}\text { FEV } \\
\text { (1) }\end{array}$ & $\begin{array}{l}\text { Mean } \\
\text { SD } \\
\mathrm{n}\end{array}$ & $\begin{array}{c}3 \cdot 79 \\
0 \cdot 82 \\
136\end{array}$ & $\begin{array}{l}4 \cdot 32 \\
0 \cdot 88 \\
45\end{array}$ & $\begin{array}{l}3 \cdot 58 \\
0 \cdot 88 \\
76\end{array}$ & $\begin{array}{c}3 \cdot 82 \\
0 \cdot 88 \\
257\end{array}$ & $\begin{array}{l}3.66 \\
0.97 \\
140\end{array}$ & $\begin{array}{l}4 \cdot 20 \\
0.94 \\
44\end{array}$ & $\begin{array}{l}3.63 \\
0.91 \\
73\end{array}$ & $\begin{array}{r}3.75 \\
0.97 \\
257\end{array}$ \\
\hline $\begin{array}{l}\mathrm{FEV} / \mathrm{H}^{2} \\
(1 \times 100)\end{array}$ & $\begin{array}{l}\text { Mean } \\
\text { SD } \\
\text { n }\end{array}$ & $\begin{array}{l}126.9 \\
24.6 \\
136\end{array}$ & $\begin{array}{c}143 \cdot 3 \\
25 \cdot 9 \\
45\end{array}$ & $\begin{array}{c}122 \cdot 6 \\
28 \cdot 1 \\
76\end{array}$ & $\begin{array}{c}128 \cdot 5 \\
26 \cdot 7 \\
257\end{array}$ & $\begin{array}{c}123 \cdot 6 \\
30 \cdot 2 \\
140\end{array}$ & $\begin{array}{c}139 \cdot 0 \\
27 \cdot 1 \\
44\end{array}$ & $\begin{array}{c}122 \cdot 3 \\
27 \cdot 5 \\
73\end{array}$ & $\begin{array}{c}125 \cdot 8 \\
29 \cdot 4 \\
257\end{array}$ \\
\hline $\begin{array}{l}\mathrm{FVC} / \mathrm{H}^{2} \\
(1 \times 100)\end{array}$ & $\begin{array}{l}\text { Mean } \\
\text { SD } \\
\mathbf{n}\end{array}$ & $\begin{array}{c}163.6 \\
28.9 \\
136\end{array}$ & $\begin{array}{c}162 \cdot 7 \\
42 \cdot 8 \\
45\end{array}$ & $\begin{array}{c}158 \cdot 7 \\
28 \cdot 0 \\
76\end{array}$ & $\begin{array}{c}161 \cdot 3 \\
32 \cdot 9 \\
257\end{array}$ & $\begin{array}{c}160 \cdot 8 \\
30 \cdot 7 \\
140\end{array}$ & $\begin{array}{c}175.7 \\
28 \cdot 7 \\
44\end{array}$ & $\begin{array}{c}160 \cdot 4 \\
26 \cdot 0 \\
73\end{array}$ & $\begin{array}{c}163 \cdot 1 \\
29 \cdot 6 \\
257\end{array}$ \\
\hline $\begin{array}{l}\text { PEF } \\
\left(1 \mathbf{s}^{-1}\right)\end{array}$ & $\begin{array}{l}\text { Mean } \\
\text { SD } \\
n\end{array}$ & $\begin{array}{r}8.40 \\
1.46 \\
136\end{array}$ & $\begin{array}{l}8.78 \\
1.00 \\
45\end{array}$ & $\begin{array}{l}8.37 \\
1.52 \\
76\end{array}$ & $\begin{array}{r}8.44 \\
1.40 \\
257\end{array}$ & $\begin{array}{r}7 \cdot 85 \\
1.74 \\
140\end{array}$ & $\begin{array}{l}8 \cdot 38 \\
1 \cdot 59 \\
44\end{array}$ & $\begin{array}{l}8 \cdot 43 \\
1 \cdot 50 \\
73\end{array}$ & $\begin{array}{r}8.08 \\
1.69 \\
257\end{array}$ \\
\hline
\end{tabular}

FEV - forced expiratory volume in one second (BTPS); FEV $/ \mathrm{H}^{2}-\mathrm{FEV}$, divided by height squared $\times 100$; FVC/ $\mathrm{H}^{2}$-forced vital capacity divided by height squared $\times 100 ; \mathrm{PEF}$ - peak expiratory fow standardised for height (see under methods).

\section{PULMONARY FUNCTION}

The results are given in table 4 . No significant differences were found between welders and controls, but smokers in both groups had a significantly smaller FEV than non-smokers $(\mathrm{p}<0.01)$. The results were further examined by age group in ten year intervals and again no differences between welders and controls were detected, except for a small difference in favour of welders for PEF in the age group 55-64 years.

The results for $\mathrm{FEV}_{1}$ are also compared with those obtained by Fletcher et al ${ }^{15}$ for workers resident in West London. The figure shows that the regression on age is very similar but that the mean is slightly higher in our subjects.

Multiple regression analysis was used to examine the factors possibly influencing $\mathrm{FEV} / \mathrm{H}^{2}$. Age was found to be by far the most important, with tobacco consumption also significant. The number of years employed in welding was not a significant factor, either in smokers or in non-smokers. Neither working in a confined space nor working without fume extraction were significant factors in determining $\mathrm{FEV} / \mathrm{H}^{2}$.

SFEV was compared in subjects with probably normal and probably abnormal chest radiographs. The 50 subjects with radiographs reported as abnormal by reader 2 had a significantly lower SFEV than subjects whose radiograph was reported as normal (normal 3.48 $\mathrm{l}$; abnormal $3.20 \mathrm{l}$ ). The consumption of tobacco did not differ between these two groups.

Comparison of SFEV revealed no differences between the following groups: welders who had worked in a confined space for more than and less than 100 days; welders who worked close to the weld as opposed to working at arm's length; welders

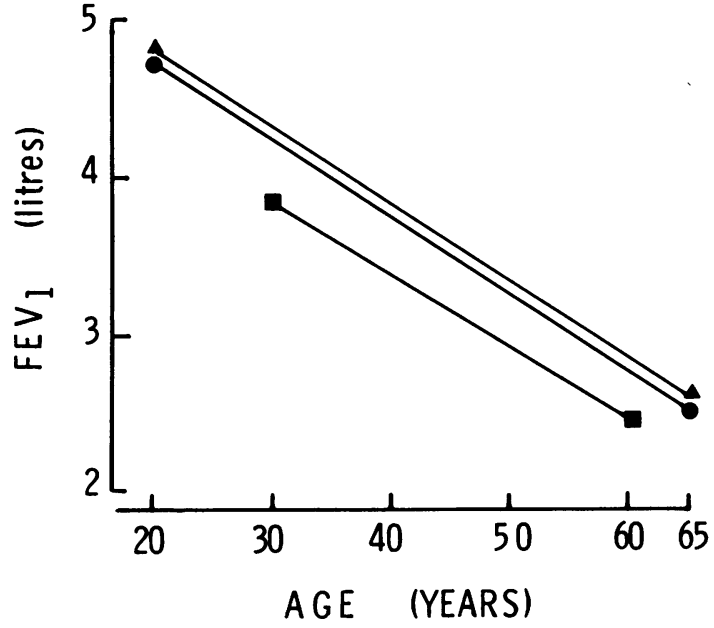

Comparison of height standardised FEV in welders $(\Delta-\Delta)$, controls $(-\longrightarrow)$, and a stratified sample from Fletcher et al's (D- Regression on age is very similar in all groups, but welders and controls had a slightly higher FEV $V_{1}$.

who were trained at a welding school compared with those who trained on the shop floor; those who did and did not wear a face mask regularly; welders who had done only arc welding (69 men) compared with those who had never used this process (144 men).

The subgroup of 186 subjects at Telford in whom measurements of flow at low lung volume were made differed in only minor respects from the subjects at Wolverhampton. SFEV was significantly larger in controls who smoked at Telford than in controls who smoked at Wolverhampton, but no differences were found between non-smokers in either group of welders. 
Table 5 Values for flow rates at low lung volumes among welders and control subjects by smoking habit

\begin{tabular}{|c|c|c|c|c|c|c|c|c|c|}
\hline & & \multicolumn{4}{|l|}{ Welders } & \multicolumn{4}{|l|}{ Controls } \\
\hline & & Smokers & Non-smokers & Ex-smokers & All & Smokers & Non-smokers & Ex-smokers & All \\
\hline$\underset{\left(1 s^{-1)^{3}}\right.}{\mathrm{MEF}_{2}}$ & $\begin{array}{l}\text { Mean } \\
\text { SD } \\
n\end{array}$ & $\begin{array}{l}1 \cdot 21^{* * *} \\
0.58\end{array}$ & $\begin{array}{l}1.91 \\
0.75 \\
24\end{array}$ & $\begin{array}{l}1 \cdot 20 \\
0 \cdot 61 \\
29\end{array}$ & $\begin{array}{c}1.37^{*} \\
0.69 \\
105\end{array}$ & $\begin{array}{l}1.59 \\
0 \cdot 72 \\
46\end{array}$ & $\begin{array}{l}1 \cdot 86 \\
0 \cdot 97 \\
13\end{array}$ & $\begin{array}{l}1.46 \\
0.70 \\
22\end{array}$ & $\begin{array}{l}1.60 \\
0.76 \\
81\end{array}$ \\
\hline$\underset{\left(1 s^{-1}\right)^{\prime O}}{\operatorname{MEF}_{0}}$ & $\begin{array}{l}\text { Mean } \\
\text { SD } \\
n\end{array}$ & $\begin{array}{l}3.35^{*} \\
1.36 \\
52\end{array}$ & $\begin{array}{l}4 \cdot 67 \\
24\end{array}$ & $\begin{array}{l}3.74 \\
1 \cdot 53 \\
29\end{array}$ & $\begin{array}{r}3.76 \\
1.50 \\
105\end{array}$ & $\begin{array}{l}3.93 \\
1.49 \\
46\end{array}$ & 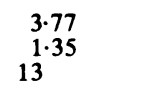 & $\begin{array}{l}3.53 \\
1 \cdot 57 \\
22\end{array}$ & $\begin{array}{r}3.79 \\
1.49 \\
81\end{array}$ \\
\hline
\end{tabular}

* $\mathrm{p}<0.05 ;{ }^{* *} \mathrm{p}<0.01$.

$\mathrm{MEF}_{25}, \mathrm{MEF}_{\mathrm{s0}}-$ maximum expiratory flow when $25 \%$ and $50 \%$ of the vital capacity remained to be expired.

Results For $\mathrm{MEF}_{25}$ and $\mathrm{MEF}_{50}$ are given in table 5. Regression analysis showed no significant relationship with height, so the values were not adjusted. In non-smokers there were no significant differences in $\mathrm{MEF}_{25}$ or $\mathrm{MEF}_{50}$ between welders and controls but among smokers values for both indices were significantly smaller in welders than in control subjects.

\section{Discussion}

The findings of this study do not provide evidence of an excess of respiratory symptoms or other features of respiratory disease in the welders. Spirometric indices were similar in the two occupational groups, although as expected the smokers had lower values than non-smokers in both. These observations were supported by the absence of correlation between the number of years employed in welding and various measures of occupational exposure to fume, including radiological signs, and spirometric indices.

The welders and control subjects were well matched. There were small differences between the populations in semi-rural Telford and those in the West Midlands conurbation, but the matching within the factories eliminated this as a complicating factor. The possibility that both groups were abnormal was examined by comparing our findings with those of Fletcher et al. ${ }^{15}$ Our subjects had fewer respiratory symptoms, tended to smoke less, and had a slightly greater mean $F E V_{1}$ but with a similar rate of decrease with age. When the differences in smoking habits were allowed for our men were very similar to the subjects in West London.

Previous reports by Oxhoj et al, ${ }^{8}$ Fogh et al, ${ }^{10}$ Hunnicutt et al, ${ }^{7}$ and Peters et $a l^{11}$ found the responses to spirometric tests to be impaired in welders who smoke. Akbarkhanzadeh ${ }^{10}$ found FEV, to be lower in welders who do not smoke. Probably differences in working conditions account for some of the discrepancies between the studies. The factories in which our subjects worked were spacious and well ventilated and conditions differed consid- $\dot{\vec{H}}$ erably from those in ship building, although we were $\vec{N}$ told that they had been less favourable in the past. 은

The possibility that our results were modified by $\vec{C}$ the loss through premature retirement or disable- $\overleftarrow{c}$ ment of some welders was investigated. We were $\overparen{D}$ able to identify welders and controls who had left $\vec{\varphi}$ employment but it was not possible to communicate $\stackrel{\infty}{\oplus}$ with them directly and the response to an indirect approach was too small to be useful. Our general inquiries did not suggest that welders left the industry because of respiratory disability.

The conclusion that emerges from our results is that welding under the conditions found in these factories does not carry an increased liability to respiratory disease. Smoking once again emerged as the most important factor contributing to the presence of respiratory symptoms and reduced ventilatory function. It was our intention to seek confirmation of these conclusions by repeating measurements after a three year interval, but large scale reduction in the labour force has precluded this.

Additional tables, which have been lodged with the Editor (copies available on request from the authors), set out data under the following headings: (a) distribution of welders and controls by age in the $\frac{D}{2}$ study population and those who declined to take part; $(b)$ cough and phlegm in welders and control o subjects by smoking habit; $(c)$ mean number of days $N$ lost due to sickness absence in the preceding two N years among welders and controls in the study popu- $\omega$ lation and in those who declined to take part, categorised according to non-respiratory illnesses.

We are grateful to Drs VH Springett and JT Hutchison for their help in reading the chest radiographs.

\section{References}

' Britton JA, Walsh EL. Health hazards of electric and gas welding. J Ind Hyg Toxicol 1940;22:125-51. 
${ }^{2}$ Gray EL. Oxides of nitrogen: their occurrence, toxicity, hazard. Arch Ind Health 1959;19:479-86.

${ }^{3}$ Stokinger EG. Ozone toxicology. Arch Environ Health 1965; 10:719-31.

${ }^{4}$ DeKretser AJ, Evans WD, Waldron HA. Carbon monoxide hazard in the $\mathrm{CO}_{2}$ welding process. Ann Occup Hyg 1964; 7:253-95.

${ }^{5}$ Challen PJR. Some news on welding and welders. J Soc Occup Med 1974;24:38-47.

- Registrar General for England and Wales. Decennial supplement on occupational mortality 1970-1972. London: HSMO, 1978.

${ }^{7}$ Hunnicutt JR, Cracovaner DJ, Myles JT. Spirometric measurements in welders. Arch Environ Health 1964;8:661-9.

${ }^{8}$ Oxhoj H, Bake B, Wedel H, Wilhelmsen L. Effects of electric arc welding on ventilatory lung function. Arch Environ Health 1979;34:211-7.

${ }^{9}$ Sevcik M, Chalupa B, Klhufkova E, Hrazdira CL. Gesundheits-schaden bei Eliktroshweissern. Zentralbl Arbeitsmed 1960;10:77-82.
${ }^{10}$ Fogh A, Frost J, Georg J. Respiratory symptoms and pulmonary function in welders. Ann Occup Hyg $1969 ; 12: 213-8$.

" Peters JM, Murphy RLH, Ferris BG, Burgess WA, Ranadive MV, Perdegrass HP. Pulmonary function in shipyard welders. Arch Environ Health 1973;26:2831.

12 Cole TJ. Height standardization of ventilatory function. Proc R Soc Med 1977;70:165-6.

${ }^{13}$ Cotes JE. Lung function: assessment and applications in medicine. 3rd ed. Oxford: Blackwell Scientific Publications, 1975.

${ }^{14}$ Nie NH, Hull $\mathrm{CH}$, Jenkins JG, Steinbrenner K, Bent DH. Statistical package for the social sciences. 2nd ed. New York: McGraw Hill, 1975.

15 Fletcher C, Peto R, Tinker C, Speizer FE. The natural history of chronic bronchitis and emphysema. Oxford: Oxford University Press, 1976.

${ }^{16}$ Akbarkhanzadeh F. Long-term effects of welding fumes upon respiratory symptoms and pulmonary function. $J$ Occup Med 1980;22:337-41. 